\title{
Gestión del Control Interno en el Sector Educación
}

\author{
José Ulises Saavedra Gómez \\ jose_saavedra02@hotmail.com \\ Escuela de posgrado \\ Universidad Cesar Vallejo \\ ORCID: 0000-0001-8792-2267 \\ José Manuel Delgado Bardales \\ jmdelgadob@ucvvirtual.edu.pe \\ Escuela de posgrado \\ Universidad César Vallejo \\ Tarapoto - Perú \\ ORCID: 0000-0001-6574-2759 \\ Scopus autor ID: 24070333700 \\ Código Renacyt: P0050554
}

\section{RESUMEN}

Esta investigación buscó caracterizar la gestión del control interno en el sector educación. El tipo de investigación es no experimental básica y el diseño de estudio es una revisión sistemática; las revisiones sistemáticas se realizaron de investigaciones científicas, cuya unidad de análisis se realizó en base a estudios originales primarios, los mismos que representan una herramienta principal para sintetizar la información científica disponible, incrementar la validez de las conclusiones de estudios individuales, así como dirimir las áreas de incertidumbre donde sea de prioridad realizar investigación. Respecto a la gestión del control interno; en donde a pesar de los esfuerzos que realizan los diferentes sectores como es educación, de acuerdo a lo investigado, se logró identificar entre los principales problemas: la deficiencia en los procesos y trámites administrativos, falta de importancia y poco interés en el control interno, falta de presupuesto para la atención en temas de resolver vacíos detectados por control interno, es por esta razón que hoy más que nunca debemos poner mayor atención y darle la importancia en todos los ámbitos al control interno.

Palabras clave: Gestión, Control Interno, Sector Educación. 


\title{
Management of Internal Control in the Education Sector
}

\begin{abstract}
:
This research sought to characterize the management of internal control in the education sector. The type of research is basic non-experimental and the study design is a systematic review; The systematic reviews were carried out of scientific investigations, whose unit of analysis was carried out based on original primary studies, which represent a main tool to synthesize the available scientific information, increase the validity of the conclusions of individual studies, as well as resolve the areas of uncertainty where research is a priority. Regarding the management of internal control; where despite the efforts made by different sectors such as education, according to the investigation, it was possible to identify among the main problems: deficiency in administrative processes and procedures, lack of importance and little interest in internal control, lack of budget for attention to issues of solving gaps detected by internal control, it is for this reason that today more than ever we must pay greater attention and give importance in all areas to internal control.
\end{abstract}

Keywords: Management, Internal Control, Education Sector.

Artículo recibido: 03 nov. 2020 Aceptado para publicación: 07 dic. 2020 Correspondencia jose_saavedra02@hotmail.com Conflictos de Interés: Ninguna que declarar 


\section{INTRODUCCIÓN}

El control interno en los procesos de contrataciones en nuestro país, se considera como el principal sistema administrativo del Estado, es previo, simultáneo y posterior, se fomenta el desarrollo organizacional, se fomenta la práctica de valores, asegura el cumplimiento normativo, se promueve la rendición de cuentas, se protege los bienes y recursos, se cuenta con información oportuna y confiable, se logra transparencia y eficiencia en las operaciones, se reduce riesgos de corrupción y se genera una cultura de prevención.

Las contrataciones del Estado, forman parte de las líneas estratégicas más predominantes de las políticas públicas y de los objetivos del Estado, su finalidad es adquirir bienes, prestar servicios y realizar obras, maximizando el valor del dinero de los contribuyentes. Hoy en día, las contrataciones públicas se fundamentan en la gestión por resultados, dándole mayor valor a los recursos públicos, su finalidad es reducir las brechas en educación, salud, saneamiento, infraestructura, seguridad ciudadana, etc.; empleando instrumentos de planificación y gestión. En las contrataciones públicas, primero se planifica luego se opera.

La organización de las contrataciones públicas y los recursos humanos deben ser evaluados periódicamente ya sea por la gestión de los procesos y el desempeño de la función en las contrataciones relacionadas con la producción de resultados y bajo responsabilidad. Desde muchos años atrás, las contrataciones del Estado, han sido engorrosas y lentas, actualmente es un tema que abarca a todos los peruanos en general. El Perú ha logrado un crecimiento económico para ayudar a los habitantes, por ello se debe tener una administración estatal que sea eficiente, y transparente, que esté respaldada por una buena gestión de las contrataciones públicas para la ciudadanía y a los más necesitados, se rigen por el código civil, a la fecha no existe uniformidad en las contrataciones directas. La corrupción es una amenaza para las contrataciones públicas; las contrataciones de la administración pública deben ser transparentes.

Los miembros que integran el comité de selección, deben ser personas capacitadas con alta capacidad moral y buenas costumbres. Los funcionarios distorsionan las leyes para posiblemente favorecer con los procesos a los proveedores.

Debemos tener en cuenta que un buen porcentaje de funcionarios estás siendo investigados por la contraloría, la fiscalía y el poder judicial por incumplir con la ley de contrataciones; debería servir como ejemplo para hacer las cosas bien. La realidad es que 
muchos funcionarios a nivel nacional no tienen miedo a ser investigados, así se han formado.

Uno de los problemas en los procedimientos de selección, es cuando se elabora las bases administrativas, copian y pegan la información de otras bases, repitiéndose el número y modalidad del proceso. Todos los acontecimientos de un proceso, deben estar registrados en el portal del SEACE, sin embargo, muchos de ellos solo se registra las bases administrativas, a pesar que existen proveedores con buena pro, los contratos suscritos no son registrados en el SEACE. El comité no respeta el cronograma de la convocatoria y si es postergada, no se comunica ante el SEACE.

Las contrataciones del Estado se enmarcan con principios y son las más vulnerables, la corrupción se ha ramificado en todas las áreas del Estado; los ciudadanos desconfían y se sienten defraudados por el actuar y proceder de los funcionarios públicos; con el buen uso de los recursos públicos, habrá mejores servicios para los pueblos más pobres y olvidados de nuestro Perú. 


\section{RESULTADOS Y DISCUSIÓN \\ RESULTADOS}

\begin{tabular}{ccc}
\hline 1. Autor & Año & $\begin{array}{c}\text { Nombre de la } \\
\text { Investigación }\end{array}$ \\
\hline $\begin{array}{c}\text { Pamilys Milagros } \\
\text { Moreno Arvelo. }\end{array}$ & 2019 & $\begin{array}{c}\text { Sistema de control } \\
\text { interno y }\end{array}$ \\
Génesis Karolina & & profesionalización de los \\
Robles Zambrano. & servidores públicos en \\
Juan Carlos Arandia & Ecuador \\
Zambrano.| & \\
\hline
\end{tabular}

\section{DATOS DE LA PUBLICACIÓN}

\section{Revista dónde se ubica la Publicación}

Revista Dilemas Contemporáneos: Educación, Política y Valores. http://www.dilemascontemporaneoseducacionpoliticayvalores.com/

\section{Volumen y}

número

Vol. 6, p1-17, 17p profesionalización de los Ecuador

\begin{tabular}{|c|c|c|c|c|c|}
\hline \multicolumn{6}{|c|}{ CONTENIDO DE LA PUBLICACIÓN } \\
\hline $\begin{array}{l}\text { Tipo de } \\
\text { Investigación }\end{array}$ & Población y muestra & Instrumentos & $\begin{array}{c}\text { Aspecto } \\
\text { éticos }\end{array}$ & S Resultados & Conclusion \\
\hline $\begin{array}{l}\text { Se empleó un } \\
\text { diseño de } \\
\text { investigación } \\
\text { bibliográfico. }\end{array}$ & $\begin{array}{l}\text { Servidores de } \\
\text { alta dirección } \\
\text { gubernamental. }\end{array}$ & $\begin{array}{l}\text { Ficha de } \\
\text { observación }\end{array}$ & $\begin{array}{l}\text { Código de } \\
\text { ética en } \\
\text { nvestigación }\end{array}$ & $\begin{array}{l}\text { El control interno es un excelente } \\
\text { mecanismo de organización y regulación } \\
\text { de la administración pública, y con ello, de } \\
\text { los recursos gubernamentales, pero para } \\
\text { cumplir su función es necesaria, su } \\
\text { interiorización en los nacionales de un } \\
\text { estado, pero sobre todo en la formación de } \\
\text { los servidores oficiales que deberán } \\
\text { aplicarlo y los jueces que deberán juzgar. }\end{array}$ & $\begin{array}{l}\text { El control interno para los órganos adscritos } \\
\text { a la administración pública de la República } \\
\text { del Ecuador está expresamente regulado en } \\
\text { la Carta Magna, en la Ley Orgánica de la } \\
\text { Contraloría General del Estado y en las } \\
\text { Normas de Control Interno para las } \\
\text { Entidades, Organismos del Sector Público y } \\
\text { de las Personas Jurídicas de Derecho } \\
\text { Privado que dispongan de Recursos } \\
\text { oficiales. }\end{array}$ \\
\hline
\end{tabular}

\begin{tabular}{|c|c|c|c|c|}
\hline \multicolumn{5}{|c|}{ DATOS DE LA PUBLICACIÓN } \\
\hline 2. Autor & Año & Nombre de la Investigación & Revista dónde se ubica la Publicación & Volumen y número \\
\hline $\begin{array}{l}\text { Yuniel Bolaño Rodríguez, } \\
\text { Esperanza Vivas Avila, }\end{array}$ & 2019 & $\begin{array}{llcc}\text { Procedimiento } & \text { para } & \text { el } \\
\text { fortalecimiento } & \text { del } & \text { sistema } & \text { de } \\
\text { control interno } & & & \end{array}$ & $\begin{array}{c}\text { Folletos } \quad \text { Gerenciales } 23 \\
\text { http://search.ebscohost.com/login.aspx? }\end{array}$ & $\begin{array}{l}\text { Vol. } 23 \text { Issue 3, p137-147. } \\
11 \mathrm{p}\end{array}$ \\
\hline
\end{tabular}




\section{Ernesto Edelberto \\ Hernández Calderín}

\begin{tabular}{|c|c|c|c|c|c|}
\hline \multicolumn{6}{|c|}{ CONTENIDO DE LA PUBLICACIÓN } \\
\hline $\begin{array}{c}\text { Tipo de } \\
\text { Investigación }\end{array}$ & $\begin{array}{c}\text { Población y } \\
\text { muestra }\end{array}$ & Instrumentos & $\begin{array}{l}\text { Aspectos } \\
\text { éticos }\end{array}$ & Resultados & Conclusion \\
\hline $\begin{array}{l}\text { Se realizó una } \\
\text { revisión } \\
\text { documental y } \\
\text { bibliográfica }\end{array}$ & $\begin{array}{c}\text { Organizaciones } \\
\text { empresariales } \\
\text { cubanas. }\end{array}$ & $\begin{array}{l}\text { Entrevistas, } \\
\text { encuestas y } \\
\text { diversos test } \\
\text { de corte } \\
\text { estadístico. }\end{array}$ & $\begin{array}{l}\text { Código de } \\
\text { ética en } \\
\text { investigación }\end{array}$ & $\begin{array}{l}\text { La aplicación del procedimiento permitió } \\
\text { la identificación de } 39 \text { riesgos y } 165 \text { causas } \\
\text { de riesgos. En el proceso de logística se } \\
\text { encuentran más del } 50 \% \text { de los riesgos y } \\
\text { causas identificadas. Se determinaron } 6 \\
\text { objetivos de control y se diseñó un plan de } \\
32 \text { acciones para su cumplimiento, el cual } \\
\text { impacta en la reducción de los riesgos en } \\
\text { un } 74 \% \text {. }\end{array}$ & $\begin{array}{l}\text { El diseño, implementación y valoración de } \\
\text { los resultados del procedimiento de gestión } \\
\text { de riesgos aportó los argumentos para } \\
\text { elaborar el plan de acciones preventivas y } \\
\text { contribuyó al fortalecimiento del Sistema de } \\
\text { Control Interno en la Empresa en estudio. }\end{array}$ \\
\hline
\end{tabular}

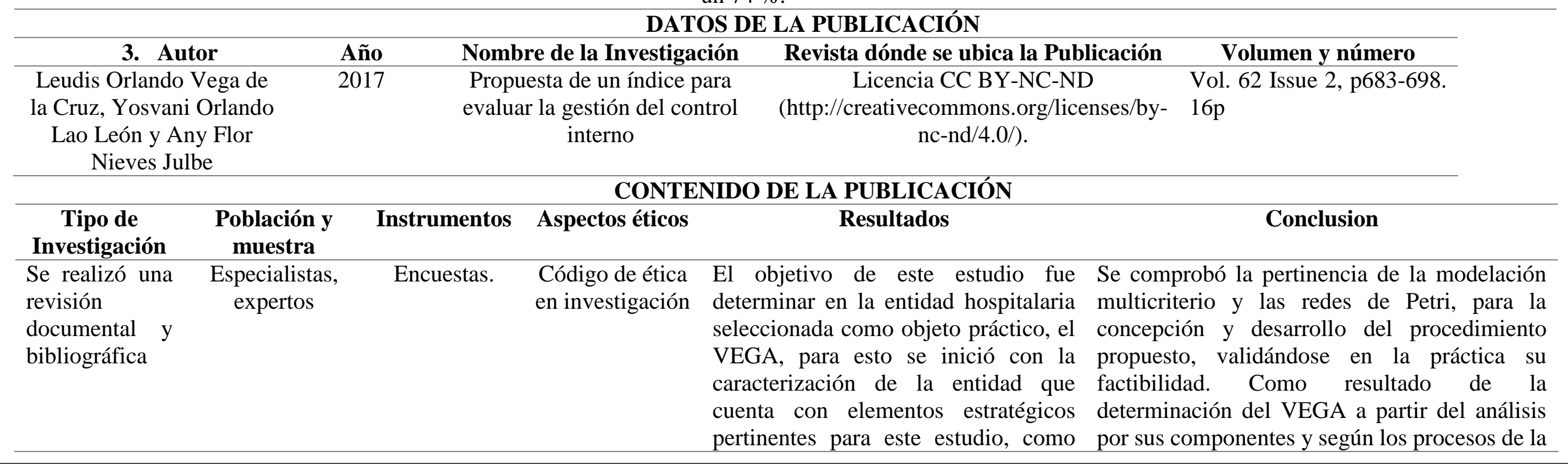


una misión, visión y objetivos de trabajo, además de los resultados de la guía de autocontrol aplicada en julio del 2015, como resultado de una auditoría externa.

\section{DATOS DE LA PUBLICACIÓN}

\begin{tabular}{ccccc}
\hline 4. Autor & Año & Nombre de la Investigación & Revista dónde se ubica la Publicación & Volumen y número \\
\hline $\begin{array}{c}\text { Alejandro del Cristo } \\
\text { Rodríguez-Morell }\end{array}$ & 2014 & El control interno y el sistema de & Licencia CC BY-NC-ND & Vol. 20, No. 1 enero-marzo \\
información. & & (http://creativecommons.org/licenses/by- & 2014 (ISSN 1025-6504).
\end{tabular}

\begin{tabular}{lccc}
\hline $\begin{array}{c}\text { Tipo y Diseño } \\
\text { de } \\
\text { Investigación }\end{array}$ & $\begin{array}{c}\text { Población y } \\
\text { muestra }\end{array}$ & Instrumentos & $\begin{array}{c}\text { COspectos } \\
\text { éticos }\end{array}$ \\
\hline $\begin{array}{l}\text { análisis- } \\
\text { síntesis, } \\
\text { inducción- } \\
\text { deducción, }\end{array}$ & $\begin{array}{c}\text { Empresas que } \\
\text { aplica este } \\
\text { sistema de } \\
\text { gestión }\end{array}$ & $\begin{array}{c}\text { Revisión } \\
\text { Bibliográfica }\end{array}$ & $\begin{array}{c}\text { y Dódigo de } \\
\text { ética en } \\
\text { investigación }\end{array}$ \\
\hline nontal & & & \\
\hline
\end{tabular}

CONTENIDO DE LA PUBLICACIÓN nc-nd/4.0/)

entidad, se concluye que aunque la entidad hospitalaria objeto de estudio práctico presenta un control interno que se evalúa como alto, pues permite detectar las principales debilidades en su gestión, existen reservas que deben ser explotadas en aras de incrementar la eficiencia en sus servicios.

\section{histórico-}

lógico

\section{Resultados}

El artículo 1 de la Resolución 60 del año 2011 de la Contraloría General de la República de Cuba define "La presente disposición tiene por objetivo establecer normas y principios básicos de obligada observancia para la Contraloría General de la República y los sujetos a las acciones de auditoría, supervisión y control de este Órgano. Constituye un modelo estándar del Sistema de Control Interno". "El control interno es el proceso integrado a las operaciones efectuadas por la dirección y el resto del personal de la empresa para proporcionar una
La importancia del estudio realizado radica en que se referencian y contrastan las normas establecidas para el componente de información y comunicación para el control interno, tanto para las empresas en perfeccionamiento empresarial, como para todas las entidades del país. Esta síntesis permite comprobar que en las normas legales analizadas existen puntos de coincidencia encaminados a hacer efectivo el componente de información y comunicación. Se enfatiza en la implementación de la Resolución 60/11 de la Contraloría General de la República y se proponen acciones para su implementación. 
seguridad razonable en el logro de los objetivos siguientes: confiabilidad de la

información, eficiencia y eficacia de

Rodríguez-Morell.

\section{DATOS DE LA PUBLICACIÓN}

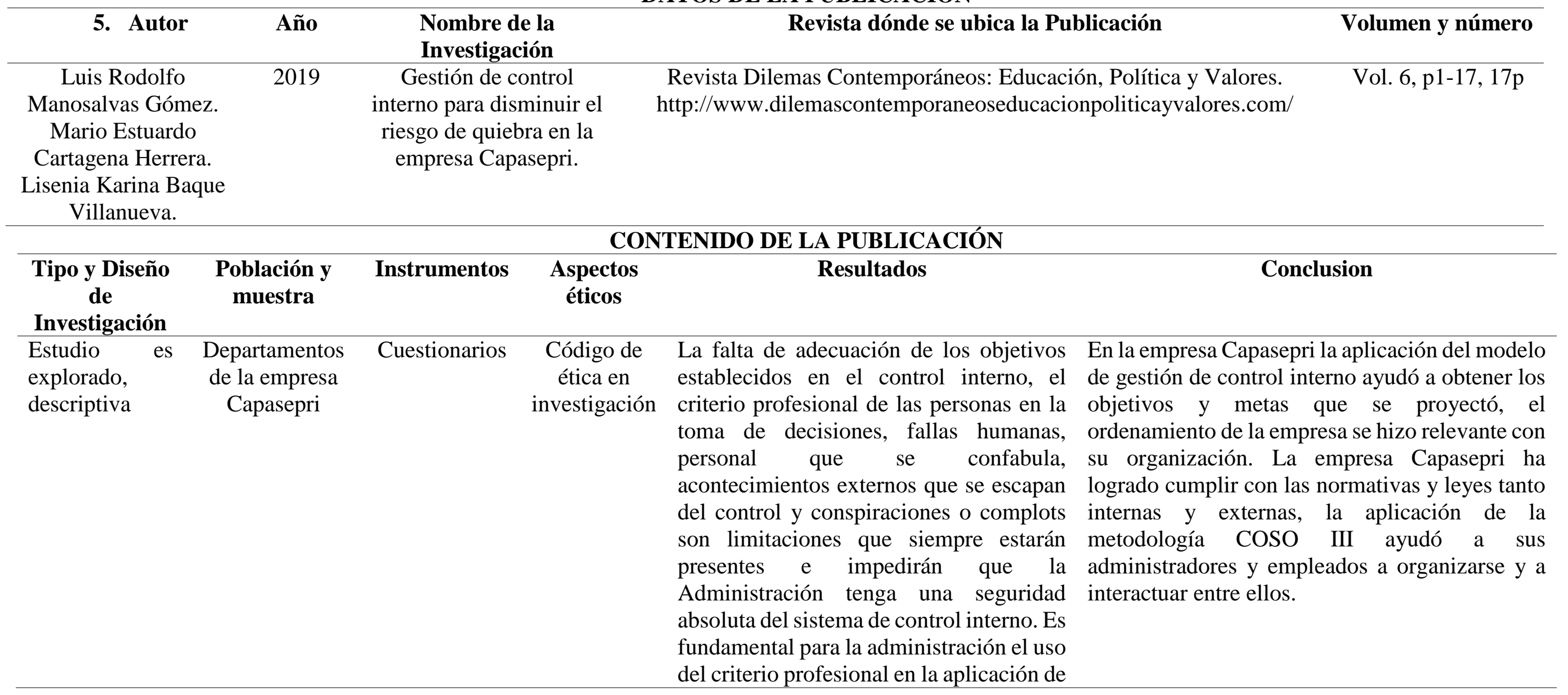


los componentes del control interno en relación con los objetivos, principios de control interno en la estructura de la entidad.

\section{DATOS DE LA PUBLICACIÓN}

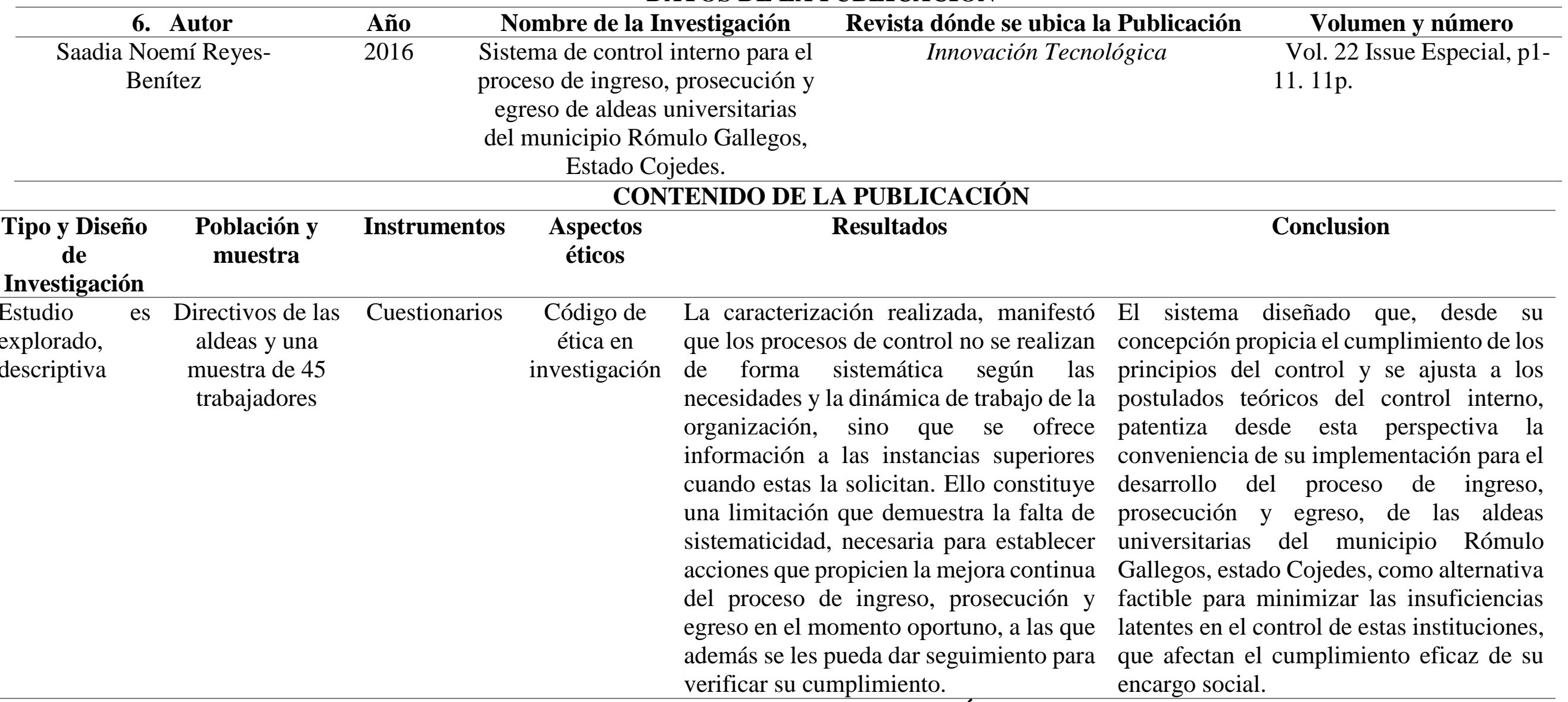

\section{DATOS DE LA PUBLICACIÓN}




\begin{tabular}{|c|c|c|c|c|}
\hline 7. Autor & Año & $\begin{array}{l}\text { Nombre de la } \\
\text { Investigación }\end{array}$ & Revista dónde se ubica la Publicación & $\begin{array}{l}\text { Volumen } \\
\text { y número }\end{array}$ \\
\hline $\begin{array}{l}\text { Julián Pablo } \\
\text { Laski }\end{array}$ & 2006 & $\begin{array}{c}\text { El control } \\
\text { interno como } \\
\text { estrategia de } \\
\text { aprendizaje } \\
\text { organizacional: } \\
\text { el Modelo } \\
\text { COSO y sus } \\
\text { alcances en } \\
\text { América Latina }\end{array}$ & http://search.ebscohost.com/login.aspx?direct=true $\& d b=f u a \& A N=32480714 \&$ lang $=e s \&$ site $=e d s$-live. & $\begin{array}{l}\text { Issue } 30, \\
\text { p9-24. } \\
16 p .\end{array}$ \\
\hline
\end{tabular}

\begin{tabular}{lclc}
\hline $\begin{array}{c}\text { Tipo y Diseño } \\
\text { de }\end{array}$ & $\begin{array}{c}\text { Población y } \\
\text { muestra }\end{array}$ & Instrumentos & $\begin{array}{c}\text { CON' } \\
\text { Aspectos } \\
\text { éticos }\end{array}$ \\
\hline $\begin{array}{l}\text { Envestigación } \\
\text { explorado, es } \\
\text { descriptiva }\end{array}$ & $\begin{array}{c}\text { Propietarios, } \\
\text { gerentes, } \\
\text { empleados y } \\
\text { otras personas } \\
\text { relacionadas con } \\
\text { la organización }\end{array}$ & Cuestionarios & $\begin{array}{c}\text { Código de } \\
\text { ética en } \\
\text { investigación }\end{array}$ \\
& & \\
\end{tabular}

\section{DATOS DE LA PUBLICACIÓN}




\begin{tabular}{|c|c|c|c|c|}
\hline 8. Autor & Año & $\begin{array}{l}\text { Nombre de la } \\
\text { Investigación }\end{array}$ & Revista dónde se ubica la Publicación & $\begin{array}{c}\text { Volumen } \\
\text { y } \\
\text { número }\end{array}$ \\
\hline $\begin{array}{c}\text { Mayra } \\
\text { Carmona } \\
\text { González } \\
\text { Yosvany } \\
\text { Barrios } \\
\text { Hernández }\end{array}$ & 2007 & $\begin{array}{c}\text { Nuevo } \\
\text { paradigma del } \\
\text { control } \\
\text { interno y su } \\
\text { impacto en la } \\
\text { gestión } \\
\text { pública }\end{array}$ & $\begin{array}{c}\text { http://search.ebscohost.com/login.aspx?direct }=\text { true } \& d b=f u a \& A N=96333076 \& l a n g=e s \& \text { site }=e d s- \\
\text { live. Acesso em }\end{array}$ & $\begin{array}{l}\text { Vol. } 141 \\
\text { Issue } 1, \\
\text { p152- } \\
\text { 171. 20p }\end{array}$ \\
\hline
\end{tabular}

\begin{tabular}{|c|c|c|c|c|c|}
\hline \multicolumn{6}{|c|}{ CONTENIDO DE LA PUBLICACION } \\
\hline $\begin{array}{c}\text { Tipo y Diseño } \\
\text { de } \\
\text { Investigación }\end{array}$ & $\begin{array}{c}\text { Población y } \\
\text { muestra }\end{array}$ & Instrumentos & $\begin{array}{l}\text { Aspectos } \\
\text { éticos }\end{array}$ & Resultados & Conclusion \\
\hline $\begin{array}{ll}\text { Estudio } & \text { es } \\
\text { explorado, } & \\
\text { descriptiva } & \end{array}$ & $\begin{array}{l}\text { Consejo de } \\
\text { Administración, } \\
\text { la dirección y el } \\
\text { resto del } \\
\text { personal de la } \\
\text { organización }\end{array}$ & Cuestionarios & $\begin{array}{c}\text { Código de } \\
\text { ética en } \\
\text { investigación }\end{array}$ & $\begin{array}{l}\text { Reflexionando sobre este último aspecto } \\
\text { los autores opinan que el informe COSO } \\
\text { deja implícita la necesidad de que los } \\
\text { controles establecidos en su alcance } \\
\text { conduzcan a la organización al } \\
\text { cumplimiento de sus objetivos, pero solo } \\
\text { enfatiza tres ámbitos: cumplimiento de las } \\
\text { operaciones, fiabilidad de la información } \\
\text { financiera y cumplimiento de las leyes, } \\
\text { quedando deficitario el objetivo } \\
\text { estratégico y cuando no se atienden los } \\
\text { controles con ese alcance se puede poner } \\
\text { en riesgo el cumplimiento de la visión y } \\
\text { misión establecidas. }\end{array}$ & $\begin{array}{l}\text { Las nuevas tendencias del control interno se } \\
\text { ajustan a la dinámica actual de la gestión } \\
\text { empresarial tanto en el sector privado como } \\
\text { en el sector público. La Dirección por } \\
\text { Objetivos y la Planeación Estratégica con } \\
\text { énfasis en los valores compartidos es hoy día } \\
\text { una práctica generalizada que requiere de un } \\
\text { tratamiento del control más allá a la } \\
\text { protección de los recursos y la confiabilidad } \\
\text { de la información financiera. La fiabilidad } \\
\text { de la información para la gestión tiene gran } \\
\text { importancia para el logro de los objetivos, } \\
\text { los controles dejan de ser rígidos y pasan a } \\
\text { ser flexibles. Ajustados según la dinámica } \\
\text { de identificación, evaluación y gestión de } \\
\text { los riesgos. }\end{array}$ \\
\hline
\end{tabular}




\section{DATOS DE LA PUBLICACIÓN}

9. Autor Año Nombre de la Investigación

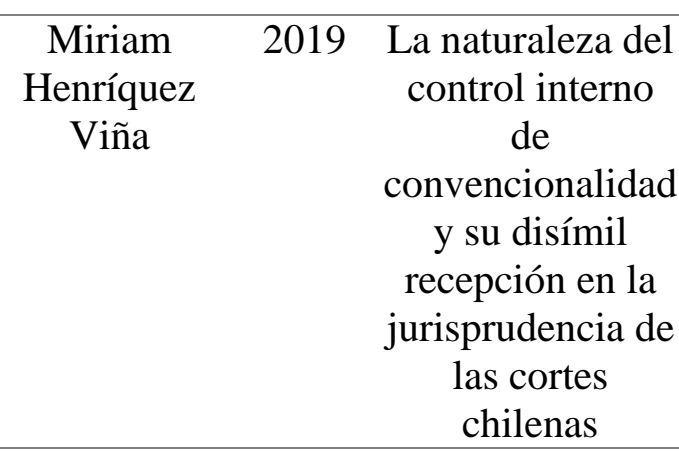

\section{Revista dónde se ubica la Publicación}

Revista Derecho del Estado

http://search.ebscohost.com/login.aspx?direct=true $\& d b=e d s g a o \& A N=e d s g c l .605910342 \&$ lang $=e s \&$ site $=e d s$ live. Acesso em
Volumen

$\mathbf{y}$

número Issue 43 , p131, 27 $\mathrm{p}$
Tipo y Diseño

Investigación

\section{Revisión}

jurisprudencial

en dos planos

\section{Población y muestra \\ Instrumentos

Aspectos
éticos

Consejo de Cuestionarios

Administración,

la dirección y el resto del

personal de la organización

\section{Código de} ética en

\section{CONTENIDO DE LA PUBLICACIÓN}

Resultados investigación

Como se advierte, la Corte Suprema considera en este último fallo al control de convencionalidad como un control de compatibilidad entre normas en el sentido de la interpretación conforme al parámetro convencional. De esta manera, en su primera sentencia, la Corte Suprema trata con ambigüedad al control de convencionalidad; en la segunda decisión, confunde el control de convencionalidad interno con el deber de cumplir una sentencia en la que el Estado chileno es condenado. 
DATOS DE LA PUBLICACIÓN

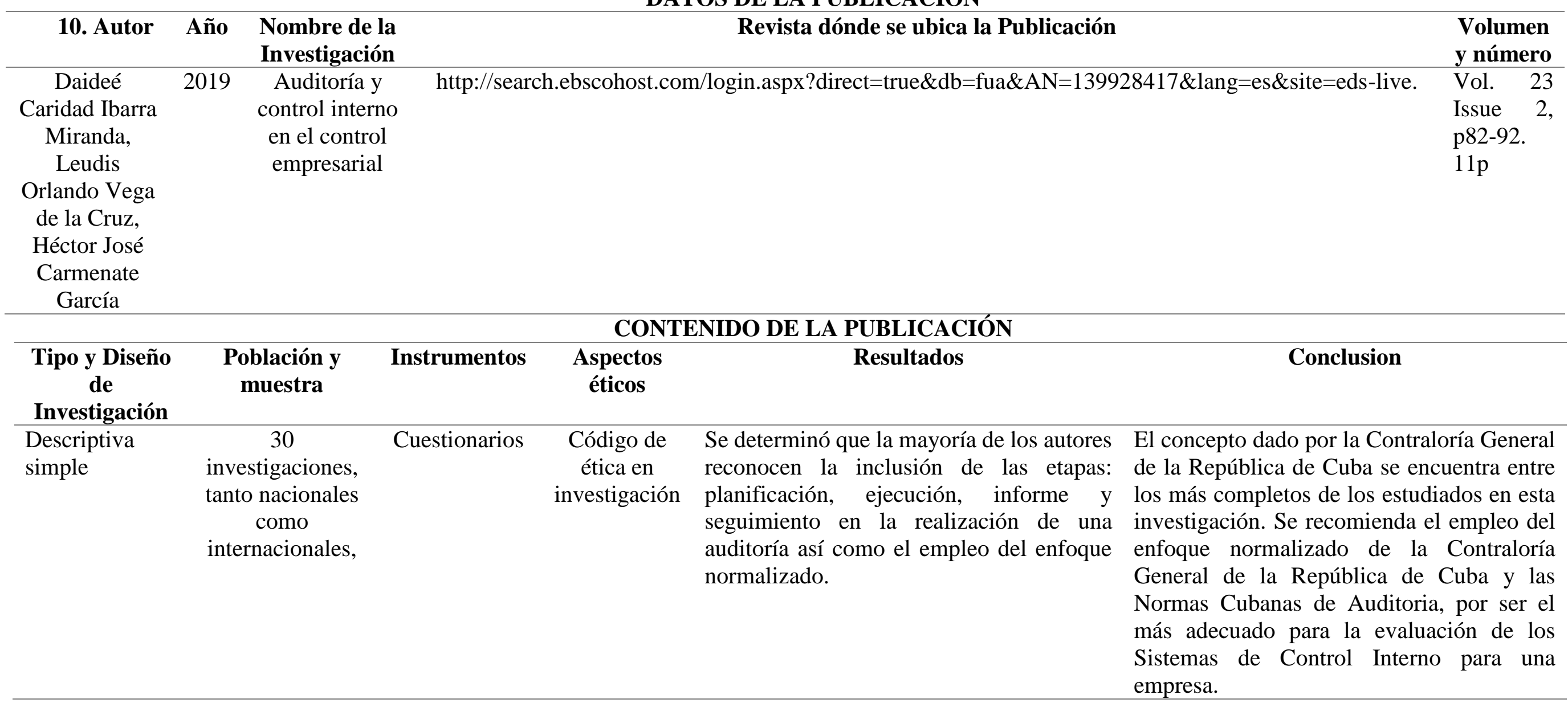




\section{DISCUSIÓN}

Posterior a la revisión sistemática de los artículos, encontramos que del 100\% corresponde a América latina y el Caribe, resaltando los países de Colombia y Perú con el $20 \%$ de publicaciones respectivamente, seguido de los países de Cuba, Paraguay, Ecuador, Argentina, Venezuela y Brasil que alcanzaron 10\% cada uno. En relación a los diseños y tipos de estudios el 100\% son descriptivos con sus diferentes variantes.

En relación a la gestión del control interno podemos resaltar que Cárdenas, Santos, Contreras, Domínguez, E.; Domínguez, J., establecen que, el diagnóstico del sistema de manejo de residuos sólidos urbanos no responde a las necesidades ambientales, sanitarias y legales. Por ello debe desarrollarse un plan estratégico ambiental que garantice el beneficio a los ciudadanos. También Rodríguez, J.; Ibarra, D., determina que la investigación contribuye al manejo de residuos sólidos para vencer el crítico actual del sistema. Por su lado Ruíz, D.; Suárez, J.; Báez, J.; Saldívar, L, concluye que, el método de Batch es una alternativa para garantizar la disposición de los desechos y transformarlos en energía limpia.

Por su parte, Mora, A.; Molina, N. establece en su estudio que, la transferencia y disposición final actual de los desechos especiales y peligrosos no evidencian una gestión acorde a la normativa, por lo que es necesario que la normativa sea socializada y determinante para que el equipo local pueda gestionar la seguridad y eliminación de residuos sólidos. Por su parte Gamboa, V., estableció que, que el gobierno local desempeñó un rol pasivo y secundario, limitándose sólo a distribuir en los domicilios de los vecinos folletos que no fortalece la intervención. También Cabañas, E.; Díaz, M.; Oliva, M., indicaron que, el tipo de residuos sólidos que más se generan son papeles, en las diferentes instituciones educativas, por ende, puede penarse en desarrollar una condición de reciclaje de estos residuos.

Sin embargo, Salas, R.; Goñas, H.; Sánchez, E, establecen que, la influencia de los factores sociales y ambientales, evidenciaron que para realizar un manejo eficiente de los residuos sólidos municipales, es necesario involucrar a la población y educar en temas ambientales. Asimismo, Sánchez, M.; Cruz, J.; Giraldo, J., determinó que, es preciso que la educación ambiental trascienda hacia la cultura ambiental, para que las acciones de los actores redunden en una gestión de residuos sólidos coherente con la economía circular. Igualmente, Tumi, J, que las prácticas de sanidad e higiene son adecuadas en la mayoría de 
familias por ende se garantiza una adecuada eliminación de residuos sólidos y en especial de protección del ambiente.

Además, Ferreira, R.; Borga, T.; Sartorel, A., determinaron que, el sistema de recolección selectiva es método eficiente para reducir los impactos ambientales, sin embargo, para obtener una buena gestión y calidad ambiental en el proceso, se debe insertar a toda la población y participar en el proceso de separación de residuos sólidos, ello debe generar responsabilidad en la población asegurando el beneficio social.

\section{CONCLUSIÓN O CONSIDERACIONES FINALES}

Se tiene que la labor estatal mayormente es cuestionada por la población, pues denota que los problemas públicos siguen existiendo, y a medida que crece el número de personas dentro de una jurisdicción, los mismos siguen incrementándose; por tanto, existe una percepción de que no se logran cumplir los objetivos de planes de desarrollo, por la dificultad de lograr la eficiencia en la implementación de las estrategias necesarias para alcanzar las metas.

En el sector público, se aprecia que los recursos presupuestales no se logran ejecutar en su plenitud al final de cada ejercicio, lo cual implica que no se logran cumplir con las metas y objetivos de los planes operativos, y ello debido a diversos factores relacionados con aspectos de competencias y habilidades de los funcionarios públicos para monitorear el cumplimiento de lo planificado; por tanto, existe una deficiencia en la aplicación de un sistema de control interno que permita a los directivos, ir midiendo los avances de la gestión, que permita generar alertas para implementar medidas correctivas adecuadas de corto plazo.

Estas falencias obedecen a múltiples causas; y una de ellas, es la existencia de debilidades institucionales en las tres instancias de gestión: Gobierno Nacional, Gobierno Regional y Gobierno Local, puesto que se han dado en los últimos años, mayores responsabilidades a los gobiernos sub nacionales originados por la transferencia de funciones y competencias, así como por el significativo incremento de sus recursos financieros, que como es natural genera una demanda sustantiva de mayores capacidades institucionales y administrativas para su adecuado uso.

Los sistemas administrativos, que fueron diseñados bajo un contexto de recursos económicos escasos, de repente se han visto obligados a operar en un ambiente de 
constante incremento de recursos y competencias, lo que habría ido en contra del uso responsable, eficaz y eficiente para el cual fueron diseñados.

Se adhiere la existencia de serias limitaciones en la fiscalización, control, y aseguramiento de la calidad interna y externa, que hace difícil la eficaz implementación de medidas preventivas y correctivas durante los procesos y las operaciones.

\section{LISTA DE REFERENCIAS}

Bolaño Y., Vivas E., Hernández E. (2019). Procedimiento para el fortalecimiento del sistema de control interno. Folletos Gerenciales 23 Vol. 23 Issue 3, p137-147. $11 \mathrm{p} \mathrm{http://search.ebscohost.com/login.aspx?}$

Carmona M, Barrios Y. (2007). Nuevo paradigma del control interno y su impacto en la gestión pública Acesso em Vol. 141 Issue 1, p152-171. 20p http://search.ebscohost.com/login.aspx?direct=true $\& d b=$ fua $\& A N=9633307$ $6 \&$ lang=es\&site=eds-live.

De la Cruz, J. (2016). El servicio del control simultáneo en las entidades sujetas al sistema nacional de control. Recuperado el 12 de enero de 2019, de: http://blog.pucp.edu.pe/blog/jdoroteo/2016/03/06/el-servicio-del-controlsimultaneo-en-lasentidades-sujetas-al-sistema-nacional-de-control/.

Gamboa, J., Puente, S. \& Vera, P. (3 de agosto de 2016). Importancia del control interno en el sector público. Revista Publicando. 3(8). 487-502. Recuperado el 18 de enero de 2019, de: file:///C:/Users/1/Downloads/DialnetImportanciaDelControlInternoEnElSectorPublico5833405.pdf

Henríquez M. (2019). La naturaleza del control interno de convencionalidad y su disímil recepción en la jurisprudencia de las cortes chilenas. Revista Derecho del Estado Acesso em Issue $\quad 43, \quad$ p131, $27 \quad \mathrm{p}$ http://search.ebscohost.com/login.aspx?direct=true $\& d b=$ edsgao $\& A N=$ edsgc $1.605910342 \&$ lang=es\&site=eds-live.

Hernández Sampieri, R., Fernández Collado, C. \& Baptista Lucio, P. (2014). Metodología de la investigación. México: McGraw-Hill Education.

Ibarra D, Vega de la Cruz L, Carmenate H. (2019). Auditoría y control interno en el control empresarial. Vol. 23 Issue 2, p82-92. $11 \mathrm{p}$ http://search.ebscohost.com/login.aspx?direct=true \&db=fua\&AN=1399284 $17 \&$ lang=es\&site=eds-live. 
Laski J. (2006). El control interno como estrategia de aprendizaje organizacional: el Modelo COSO y sus alcances en América Latina. Issue 30, p9-24. 16p. http://search.ebscohost.com/login.aspx?direct=true \&db=fua\&AN=3248071 4\&lang=es\&site=eds-live.

Manosalvas L., Cartagena M., Baque L. (2019). Gestión de control interno para disminuir el riesgo de quiebra en la empresa Capasepri. Revista Dilemas Contemporáneos: Educación, Política y Valores. Vol. 6, p1-17, 17p http://www.dilemascontemporaneoseducacionpoliticayvalores.com/

Moreno P., Robles G., Arandia J.|(2019). Sistema de control interno y profesionalización de los servidores públicos en ecuador revista dilemas contemporáneos: educación, política y valores. vol. 6, p1-17, 17p http://www.dilemascontemporaneoseducacionpoliticayvalores.com/

Resolución No. 60 (2011). Normas del Sistema de Control Interno. Contraloría General de la República. Edición extraordinaria No. 13. Gaceta Oficial de la República de Cuba. La Habana. Recuperado de http://www.gacetaoficial.cu/.

Reyes-Benítez S. (2016). Sistema de control interno para el proceso de ingreso, prosecución y egreso de aldeas universitarias del municipio Rómulo Gallegos, Estado Cojedes. Innovación Tecnológica. Vol. 22 Issue Especial, p1-11. 11p.

Rodríguez-Morell A. (2014) El control interno y el sistema de información. Licencia CC BY-NC-ND Vol. 20, No. 1 enero-marzo 2014 (ISSN 10256504). (http://creativecommons.org/licenses/by-nc-nd/4.0/).

Vega L., Lao Y., Nieves A. (2017). Propuesta de un índice para evaluar la gestión del control interno Licencia CC BY-NC-ND Vol. 62 Issue 2, p683-698. 16p (http://creativecommons.org/licenses/by-nc-nd/4.0/) 